\title{
KARAKTER FASAD SUATU KELOMPOK BANGUNAN RUKO CINA MELAYU PADA KORIDOR JALAN JAMIN GINTING PANCUR BATU
}

\author{
Almira Raissa ${ }^{1}$, Beny O.Y Marpaung ${ }^{2}$ \\ ${ }^{1}$ Jurusan Arsitektur, Fakultas Teknik, Universitas Sumatera Utara \\ ${ }^{2}$ Jurusan Arsitektur, Fakultas Teknik, Universitas Sumatera Utara \\ Jl. Perpustakaan St. J07 Building, Medan, 20155, Indonesia \\ *Email: 1raissaariman@yahoo.com, 2beny.marpaung@usu.ac.id
}

\begin{abstract}
ABSTRAK
Kecamatan Pancur Batu merupakan salah satu daerah yang memiliki peranan penting dalam perkembangan perusahaan tembakau Belanda di Deli. Kegiatan perkebunan tembakau tersebut mengakibatkan kehadiran orang-orang Tionghoa yang bekerja sebagai pekerja kontrak di perusahaan perkebunan Belanda. Kenyataan inilah yang menjadi awal warga keturunan Tionghoa mewarnai kehidupan di Pancur Batu hingga hari ini khususnya pada kawasan pasar. Warga Tionghoa yang berdiam pada area kedai panjang atau deretan ruko pada koridor Jalan Jamin Ginting Pancur Batu memilih pekerjaan sebagai pedagang. Kenyataannya pengaruh budaya Tionghoa dapat ditemukan pada kelompok bangunan ruko di kawasan pasar Pancur Batu dan menjadi daya tarik bagi kawasan tersebut. Seiring berjalannya waktu, pengalihan pemilik bangunan menyebabkan ruko-ruko tersebut tidak terawat lagi dan menghilangnya aksen Tionghoa pada setiap elemen bangunan. Identifikasi karakter fasad kelompok bangunan ruko ini bertujuan untuk mengembalikan citra kawasan pasar sebagai pusat perdagangan yang dibentuk oleh warga Tionghoa. Penelitian ini menggunakan metode analisis deskriptif kualitatif. Adapun penelitian ini akan menghasilkan pedoman dalam hal melestarikan kelompok bangunan ruko aksen Tionghoa pada koridor Jalan Jamin Ginting Pancur Batu. Dengan menerapkan pedoman pelestarian bangunan ruko aksen Tionghoa tersebut diharapkan dapat mengembalikan citra kawasan pasar pada koridor Jalan Jamin Ginting Pancur Batu.
\end{abstract}

Kata Kunci: Etnis Tionghoa, Fasad Bangunan Ruko, Citra Kawasan, Pelestarian Bangunan.

\section{PENDAHULUAN}

Kota merupakan suatu perwujudan dari aktifitas manusia yang senantiasa mengalami perubahan dari waktu ke waktu. Berdasarkan sejarahnya Kecamatan Pancur Batu merupakan salah satu daerah yang menjadi jalur untuk perusahaan tembakau deli dan sekaligus menjadi pusat pemerintahan Kolonial Belanda. Pada tahun 1900-an, Kecamatan Pancur Batu dibawah kepemimpinan Kolonial Belanda memiliki perusahaan tembakau. Oleh karena itu banyak pendatang yang berasal dari Cina dan Jawa yang datang ke Pancur Batu untuk diperkerjakan sebagai pekerja kontrak di perusahaan tembakau tersebut, inilah penyebab warga Tionghoa mewarnai kehidupan di Kecamatan Pancur Batu. Namun karena adanya serangan Belanda, maka penduduk Cina dan
Jawa memilih untuk mengungsi dan menetap di daerah pasar atau los di Pancur Batu.

Kebanyakan dari warga Tionghoa memilih pekerjaan berdagang sebagai pekerjaan tetap mereka hingga sekarang. Sebagai bukti sejarah tersebut, masih terdapat kelompok bangunan ruko pengaruh arsitektur Cina yaitu tepat berada didepan pasar Pancur Batu (Gambar 1). 


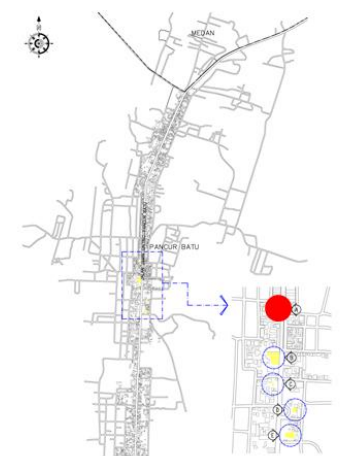

Gambar 1. Lokasi Deretan Bangunan Ruko Cina Melayu di Pancur Batu

Namun, seiring berjalannya waktu dan pengalihan pemilik bangunan menyebabkan fisik fasad ruko menjadi tidak terawat (Gambar 2).

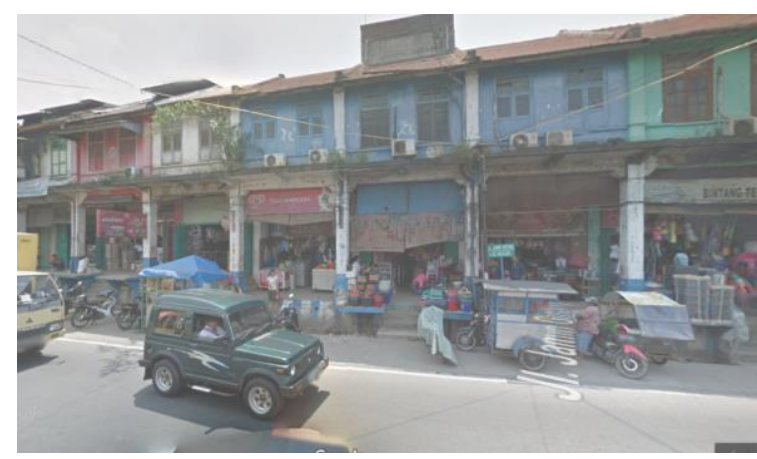

Gambar 2. Kondisi Fisik Fasad Bangunan Ruko Cina Melayu di Pancur Batu

Kondisi fisik bangunan ruko yang tidak terawat dapat dilihat melalui beberapa elemen bangunan seperti jendela dan dinding yang sudah rusak, keadaan tersebut menghilangkan karakter ruang sebagai sejarah pada koridor Jalan Jamin Ginting Pancur Batu. Karakter sosial budaya masyarakat melatarbelakangi bentuk fisik suatu lingkungan. Sehingga untuk mengetahui karakter ruang suatu kawasan sangat perlu mengkaji sekilas karakter non fisik yang melatarbelakangi pembentukan fisik suatu kelompok bangunan ruko Cina Melayu pada koridor Jalan Jamin Ginting Pancur Batu (Rapoport, 1977).

Bentukan fisik (bangunan, vegetasi dan tanah) sebagai pembentuk ruang yang berada di tepi (sisi) ruang jalan sangat menentukan karakter kawasan sepanjang jalan tersebut (Misavan, 2013). Karakter visual dapat dilihat melalui petunjuk visual yang merupakan images perception yang dirasakan dengan mata (Ching,
1995). Yang dapat mempengaruhi karakter visual kawasan adalah karakter bangunan, karakter lingkungan serta integrasi karakter bangunan dan lingkungan (Cullen, 1961). Karakter bangunan merupakan fenomena fisik terkait hubungan antar bangunan dengan teori bentuk dan massa. Bangunan ruko cina melayu adalah sebuah objek yang dapat dijadikan landmark atau focal point pada koridor tersebut sesuai dengan images perception yang ditangkap oleh pengguna jalan yang melintasi koridor (Shirvani, 1984).

Karakter visual sebuah kota juga dapat dihadirkan melalui penghubung visual yang dapat terealisasi dengan adanya kesamaan visual antara satu bangunan dengan bangunan lain dalam suatu kawasan sehingga dapat menimbulkan suatu image (Rizqiyah, 2016). Kondisi visual suatu kota sangat erat kaitannya dengan fenomena yang berkaitan dengan visual fisik dan dapat menimbulkan rasa yang bersifat emosional, serta fenomena fisik yang berkaitan dengan fisik suatu bangunan dan penataannya (Cullen, 1961).

Melihat karakter visual secara keseluruhan, terdapat beberapa elemen fisik terkait karakter pada bangunan yaitu: bentuk bangunan, bentuk bukaan, bentuk atap, material bangunan, tanda pada bangunan, warna bangunan, elemen vertikal (kolom) dan elemen horizontal (balok) (Berry, 1980).

Bangunan ruko Cina Melayu dianggap dapat menjadi potensi yang menyangkut warisan budaya di koridor tersebut. Potensi tersebut diakibatkan karena posisi kelompok bangunan ruko yang berada pada jalur utama lintas Kota Medan menuju pusat wisata Sibolangit, sehingga apabila deretan bangunan ruko Cina Melayu dikembalikan fasadnya seperti sediakala akan meningkatkan nilai dan karakter ruang kawasan sehingga dapat menambah daya tarik visual. Hal tersebut dapat diraih melalui pelestarian dan pemugaran. Menurut UndangUndang Republik Indonesia nomor 11 tahun 2010 tentang Cagar Budaya, jika ditinjau melalui usia bangunan dan arti khusus bagi sejarah, deretan bangunan ruko cina melayu pada koridor Jalan Jamin Ginting Pancur Batu dapat dikatakan sebagai bangunan cagar budaya. Pemugaran dan pelestarian dapat dilakukan dengan cara mengembalikan kondisi fisik lalu memepertahankannya.

Bangunan seperti kelompok bangunan ruko Cina Melayu pada koridor Jalan Jamin 
ginting Pancur Batu memiliki kemiripan dengan bangunan ruko di Singapore yang diklasifikasikan sebagai early shophouse style tahun 1840-1900 yang dinobatkan sebagai bangunan yang dikonservasi dan dipreservasi oleh Pemerintah Singapura (Gambar 3) (Urban Redevelopmen Authority, 2011).

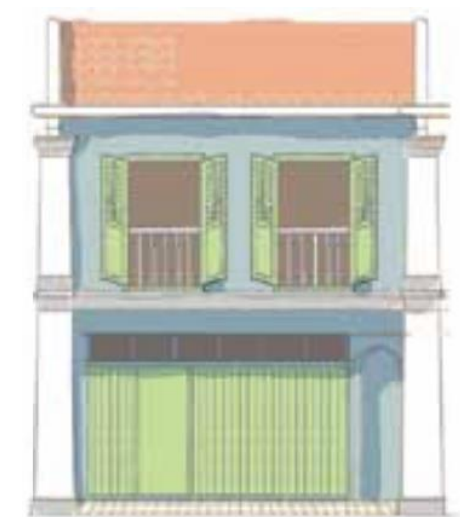

Gambar 3. Early Shophouse Style di Singapura

Salah satu kebijakan Pemerintah Singapura dalam melakukan konservasi adalah adaptive reuse, yaitu mengaktifkan kembali bangunan ruko. Prinsip adaptive reuse adalah cara dimana bangunan diaktifkan kembali untuk fungsi yang sama atau berbeda dari yang seharusnya dan dimaksudkan agar bangunan terpakai hingga bangunan tersebut tidak rusak dan terawat. Konsep adaptive reuse tidak sekedar mengembalikan tampilan fisik arsitektur melainkan berusaha menghormati dan menghargai nilai sejarah yang terdapat pada bangunan (Austin dalam Sofiana et. al., 2014).

Fisik yang paling terlihat dari suatu bangunan adalah warna dan struktur bangunan, maka hal yang paling mudah dilakukan adalah pengaplikasian warna dan memperbaiki struktur bangunan sehingga mampu menjelaskan karakter bangunan tersebut. Arsitektur Cina memiliki beberapa warna yang sering diaplikasikan pada bangunan yaitu warna merah, warna hijau, warna kuning dan warna biru (Moedjion, 2011).

\section{METODE PENELITIAN}

Penelitian ini menggunakan metode deskriptif kualitatif dimana data didapatkan melalui analisa teori, studi banding dan pengamatan langsung terkait kondisi eksisting. untuk memudahkan penelitian, peneliti menghubungkan permasalahan terkait shophouse yang ada di Singapura dengan deretan bangunan ruko Cina melayu yang ada pada koridor Jalan Jamin Ginting Pancur Batu.

Metode deskriptif kualitatif dalam penelitian ini juga dilakukan dengan cara penggambaran langsung kondisi eksisting deretan bangunan ruko cina melalui teknik dokumentasi (foto) dan kemudian diilustrasikan ulang ke dalam bentuk gambar 2D melalui software autocad, selanjutnya hasil foto dapat langsung dibandingkan dengan hasil dari kajian teori atau studi banding proyek sejenis yang ada di Singapura. Hal ini dilakukan untuk memperjelas karakter fasad kelompok bangunan yang diteliti dengan bangunan ruko arsitektur cina melayu yang ada pada studi banding sehingga mempermudah peneliti menjawab permasalahan penelitian.

\section{HASIL DAN PEMBAHASAN}

Kelompok bangunan ruko cina melayu yang terletak pada segmen pasar di koridor Jalan Jamin Ginting Pancur Batu merupakan potensi yang dimiliki kawasan tersebut. Potensi tersebut dibentuk oleh sejarah hadirnya bangunan ruko cina melayu dan gaya arsitektur yang mencolok serta berbeda dengan deretan ruko yang berada dekat dengan deretan ruko cina melayu. Karakter fasad deretan ruko ini sangat kuat kaitannya dengan early shophouse yang ada di Singapura. Sebagai tujuan untuk penguatan karakter visual koridor Jalan Jamin Ginting Pancur Batu, kelompok bangunan ruko yang menjadi bukti dari sejarah pembentukkan kawasan sangat perlu untuk dipreservasi dengan prinsip adaptive reuse. Adaptive reuse juga dapat dilakukan dengan tujuan agar bangunan ruko menjadi aktif sehingga bangunan tetap terawat.

Pelestarian kelompok bangunan ruko Cina Melayu pada koridor ini sangat memiliki potensi yang signifikan bagi perkembangan kawasan, yaitu: letak bangunan yang beriorientasi pada satu-satunya jalan lintas menuju kawasan wisata sehingga dapat menjadi 
daya tarik bagi kawasan, dan jika bangunan tersebut dilestarikan dengan prinsip adaptive reuse, maka dapat meningkatkan perekonomian kawasan.

Hasil dari pengumpulan data berupa dokumentasi foto bangunan ruko Cina Melayu digambarkan kedalam gambar 2D menggunakan program autocad (Gambar 4).

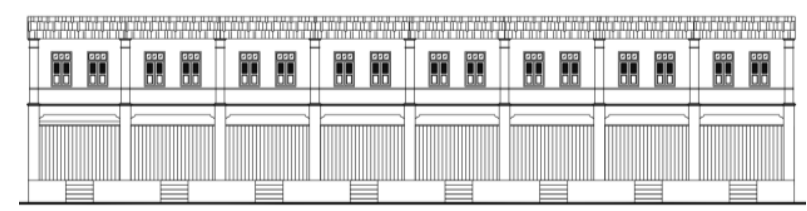

Gambar 4. Ilustrasi Kondisi Eksisting Bangunan dalam Gambar 2D

Hasil dokumentasi keadaan eksisting tersebut kemudian dibuat perbandingan dengan kajian studi literatur early shophouse di Singapura (Gambar 5).
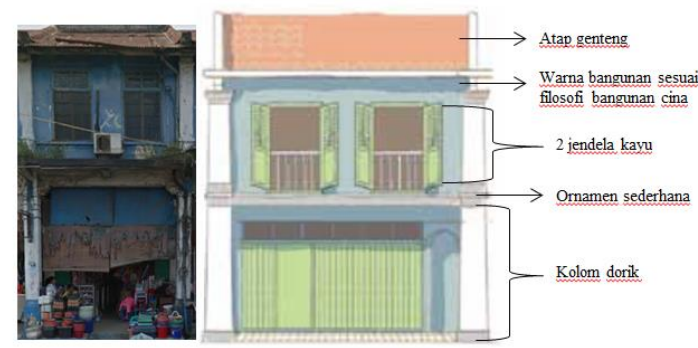

Gambar 5. Perbandingan Detail Bangunan Eksisting dengan Studi Banding

Secara umum, early shophouse adalah bangunan ruko dengan 2 lantai dan memiliki kolom dorik. Bangunan ruko degan tipe ini memiliki ornament yang sedikit. Bangunan ini memiliki dua jendela kayu pada lantai atas dan kanopi dengan material genteng. Umumnya karakter bangunan ini mengandung unsur-unsur keberuntungan sesuai dengan filosifi bangunan cina, karakter ini sering dituangkan dalam pewarnaan bangunan.

Kondisi fisik kelompok bangunan ruko Cina Melayu pada koridor Jalan Jamin Ginting Pancur Batu tidak banyak mengalami perubahan bentuk, hanya saja dirusak oleh penempatan signage yang tidak beraturan dan warna bangunan yang tidak dirawat oleh pemilik. Oleh karena itu, pelu dilakukannya pelestarian kelompok bangunan ruko agar menjaga bangunan tersebut sehingga tidak rusak dan terawat. Pelestarian deretan bangunan dilakukan melalui pewarnaan ulang bangunan dan pengembalian kondisi struktur bangunan. Hal serupa juga dilakukan oleh pemerintah Singapura guna meningkatkan karakter visual koridor dimana bangunan-bangunan ruko cina tersebut berada.

\section{Warna Bangunan}

Dari hasil penelitian yang dilakukan terhadap deretan bangunan ruko cina melayu ditemukan beberapa permasalahan terkait warna bangunan yang sudah mulai pudar dan tidak serasi dengan bangunan-bangunan ruko disebelahnya serta kerusakan elemen-elemen bangunan yang mengganggu visual fasad bangunan ruko tersebut (Gambar 6).

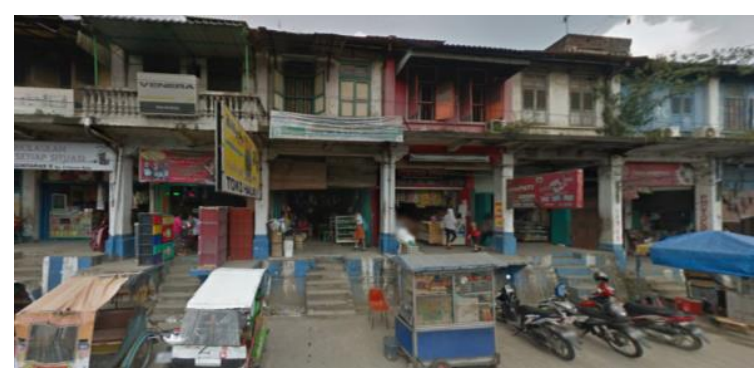

Gambar 6 Warna Bangunan Deretan Ruko Cina Melayu di Pancur Batu

Kondisi fasad bangunan seperti ini dapat menurunkan karakter visual pada koridor Jalan Jamin Ginting karena deretan bangunan ruko ini merupakan salah satu potensi yang dimiliki oleh koridor, Untuk meningkatkan karakter visual kawasan perlu memperhatikan keseragaman visual pada kelompok bangunan ruko Cina Melayu dapat dilakukan dengan mengadopsi warna-warna yang umum digunakan pada bangunan Cina (Gambar 7).

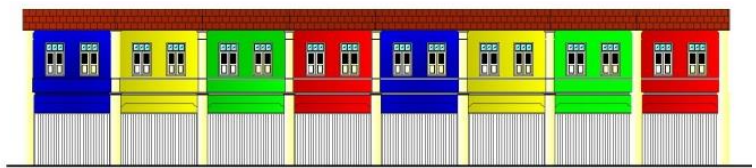

Gambar 7. Ilustrasi Hasil Pelestarian Bangunan Terkait Warna

Warna-warna yang umum digunakan pada bangunan Cina umumnya memiliki makna tersendiri, warna-warna tersebut adalah: 
a. Merah: unsur api, melambangkan kegembiraan, keberuntungan, harapan dan kebahagiaan.

b. Hijau: unsur kayu, melambangkan panjang umur, pertumbuhan dan keabadian.

c. Kuning: unsur tanah, melambangkan kekuatan dan kekuasaan.

d. Biru: berkaitan dengan dewa-dewa.

\section{Jendela}

Kondisi jendela bangunan ruko Cina melayu saat ini terlihat tidak terawatt, hal ini disebabkan oleh rusaknya kayu yang digunakan sebagai material jendela dan tidak dirawat oleh pemilik ruko (Gambar 8).

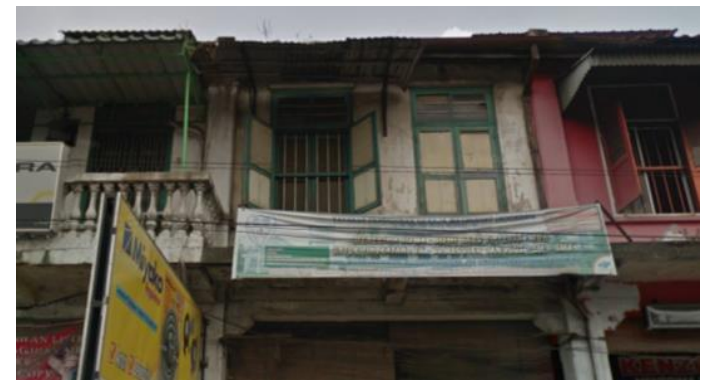

Gambar 8. Kondisi Fisik Bangunan Ruko Cina Melayu di Pancur Batu pada Bagian Jendela

Sebagai usaha dari pelestarian bangunan, jendela bangunan pada lantai 2 akan dikembalikan bentuknya seperti jendela pada bangunan ruko Cina di Singapura dengan tipe early shophouse (Gambar 9 dan 10).

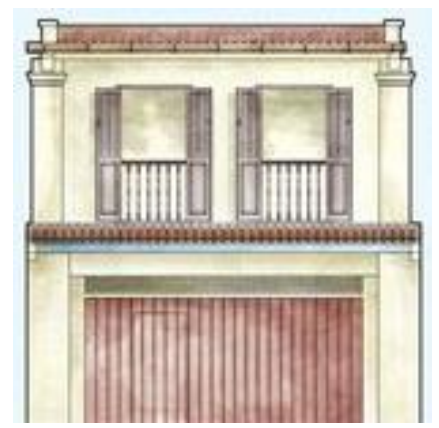

Gambar 9 Desain Jendela pada Early Shophouse di Singapura

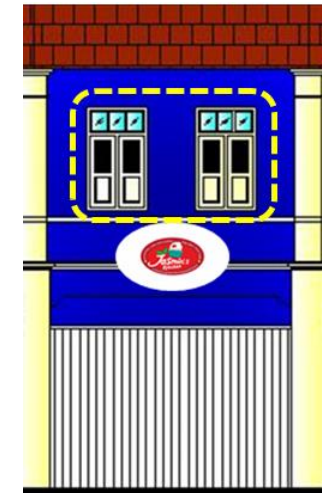

Gambar 10. Ilustrasi Hasil Pelestarian Bangunan Terkait Jendela

Umumnya, jendela pada bangunan ruko cina dengan tipe early shophouse di Singapura memiliki dua buah jendela dengan material kayu.

\section{Kolom Dorik}

Bangunan ruko Cina melayu pada koridor Jalan Jamin Ginting Pancur Batu sudah memiliki kolom dorik sesuai dengan yang terdapat pada bangunan ruko tipe early shophouse di Singapura dan tidak terjadi perubahan bentuk dan struktur. Kolom dorik pada bangunan ruko cina melayu yang terdapat pada koridor Jalan Jamin Ginting Pancur Batu hanya memiliki kerusakan seperti batu-bata yang mengelupas dan warna yang memudar (Gambar 11).

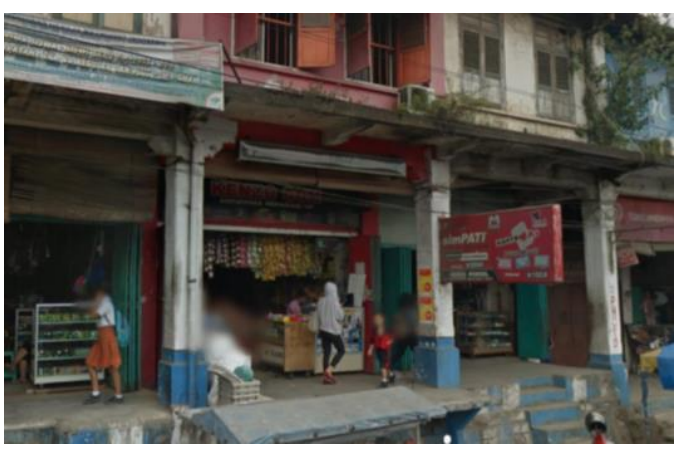

Gambar 11. Kolom pada Bangunan Ruko Cina Melayu di Pancur Batu Tampak Sudah Tidak Terawat

Keadaan kolom dorik pada bangunan ruko Cina melayu yang sudah tidak terawat dan rusak sangat berpengaruh pada visual bangunan dan mempengaruhi karakter visual koridor. Untuk meningkatkan karakter visual koridor, peneliti mengadopsi kolom dorik yang 
digunakan pada bangunan-bangunan ruko di Singapura (Gambar 12 dan 13).

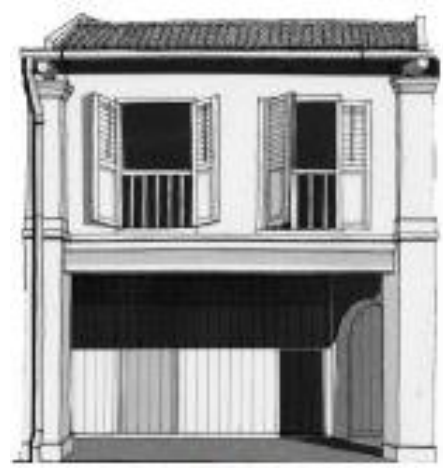

Gambar 12. Kolom Dorik yang Terdapat pada Early Shophouse di Singapura

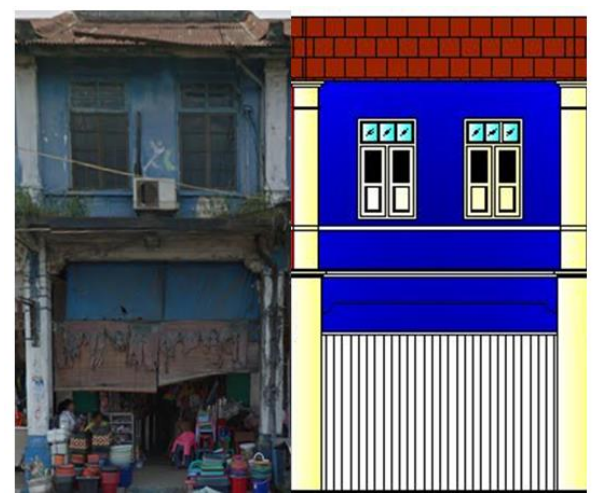

Gambar 13. Ilustrasi Hasil Pelestarian Bangunan Terkait Kolom Dorik

\section{Signage (Tata Informasi)}

Kondisi bangunan ruko saat ini yang ditutupi oleh sistem tata informasi yang terkesan semraut dan sangat menggangggu visual koridor Jalan Jamin Ginting Pancur Batu (Gambar 14).

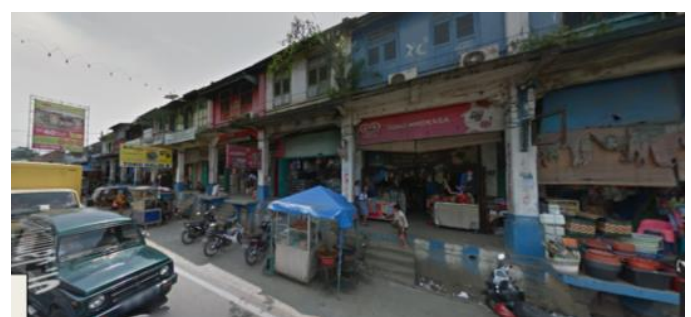

Gambar 14. Kondisi Bangunan Ruko Cina Melayu yang Ditutupi oleh Sistem Tata Informasi di Pancur Batu

Jika bangunan digunakan sebagai bangunan komersial, penggunaan signage system dianggap sangat penting. Bangunan ruko cina melayu yang mengadopsi prinsip adaptive reuse akan tetap digunakan sebagai bangunan komersial seperti kondisi eksisting, namun penempatan signage system tidak boleh merusak dan menghalang fasad bangunan ruko cina melayu. Penempatan signage bisa pada area kosong pada bagian atas lantai (gambar 15).

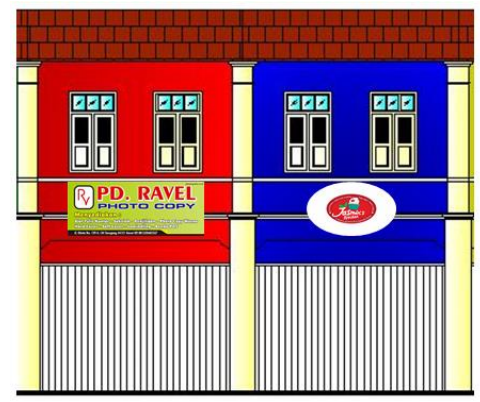

Gambar 15 Ilustrasi Hasil Pelestarian Bangunan Terkait Signage System

\section{KESIMPULAN}

Kelompok bangunan ruko Cina Melayu pada koridor Jalan Jamin Ginting Pancur Batu merupakan bukti bahwa koridor tersebut pernah menjadi kawasan yang menjadi bibit dari perkembangan kawasan. Seiring berjalannya waktu dan pengalihan pemilik bangunan, kerusakan sering terjadi pada bangunan ruko Cina Melayu sehingga menghilangkan karakter bngunan itu sendiri dan karakter kawasan pasar Pancur Batu yang menjadi cikal bakal pertumbuhan kota pada masa itu. Sebenarnya, kelompok bangunan ruko ini telah menjadi daya tarik untuk Pancur Batu. Hal ini yang menyebabkan perlu dilakukannya pelestarian bangunan.

Pelestarian bangunan dilakukan dengan mengembalikan dan memperbaiki bangunan ke bentuk semula, sehingga karakter fasad semakin jelas. Pelestarian bangunan ruko Cina Melayu pada koridor Jalan Jamin Ginting dianggap mampu meningkatkan karakter ruang pada kawasan melalui sejarah. Hal ini juga menjadi potensi yang dapat membangun kawasan. Selain itu prinsip adaptive reuse juga dapat meningkatkan nilai lahan, nilai lingkungan dan menjaga identitas kawasan. Dengan mengembalikan karakter fasad bangunan ruko Cina Melayu pada koridor Jalan Jamin Ginting Pancur Batu maka akan meningkatkan karakter visual koridor sekaligus mampu menjadi landamark baru dan focal point.

\section{Daftar Pustaka}


Berry, Wendell (1980) Good Neighbors;

Urban Redevelopment Authority

(2011)

Building Next to History. State: Conservation Guidelines, Singapore.

Historical Society of Colorado.

Ching, Francis D.K (1995) A Visual Dictionary of Architecture, New York; Van Nostrand Reinhold.

Cullen, Gordon (1961) The Concise of Townscape, Van Nostrand reinhold Company, New York.

Misavan, D., Jumaylinda, B. (2013) Pengaruh Pembaruan Fasad Bangunan Terhadap Karakter Visual Kawasan, Jurnal Online Mahasiswa Fakultas Teknik Untan, I (11), 1-13.

Moedjiono (2011) Ragam Hias dan Warna Sebagai Simbol dalam Arsitektur Cina, Modul, 11 (1), 17-22.

Rapoport, Amos (1977) Human Aspects of urban Form, Towards A Man Enviroment Approach to Urban Form and Design, Oxford, USA.

Rizqiyah, Fardilla (2016) Arahan Desain Fasad Koridor Jalan Songoyudan untuk Memperkuat Citra Visual pada Area Perdagangan Bersejarah di Surabaya, EMORA Indonesian Journal of Architecture, 2 (1), 13-20.

Shirvani, Hamid (1984) The Urban Design Process, Van Nostrand Reinhold Company, New York.

Sofiana, R., Purwantiasning, Ari W., Anisa, 2014. Strategi Penerapan konsep Adaptive Re-use pada Bangunan Tua Studi Kasus: Gedung PT P.P.I (Ex. Kantor PT Tjipta Niaga) di Kawasan kota Tua Jakarta, Seminar Nasional Sains dan Teknologi, 1-10.

Undang-Undang Republik Indonesia nomor 11 tahun 2010 tentang Cagar Budaya. 24 November 2010. Lembaran Negara Republik Indonesia tahun 2010 nomor 130. Jakarta. 